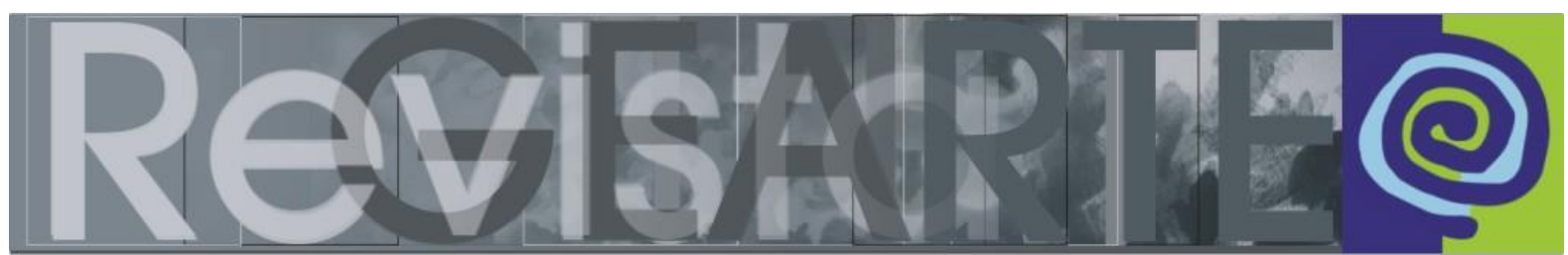

ISSN 2357-9854 | e-ISSN 2596-3198 (online)

\title{
Formación del profesorado de Primaria defendiendo la diversidad y la inclusión. Memoria de un caso de experiencia docente a través de Musearí
}

\author{
Ricard Huerta \\ (Universitat de València — UV, València, España)
}

\begin{abstract}
RESUMEN - Formación del profesorado de Primaria defendiendo la diversidad y la inclusión. Memoria de un caso de experiencia docente a través de Museari - Entre las posibilidades de la educación artística conviene destacar las cuestiones de reivindicación social, especialmente la lucha por la equidad y el respeto hacia las minorías. Dentro de esta corriente socializadora se enmarcan los avances en materia de género y diversidad. La lucha por los derechos humanos se convierte así en un lugar común desde el cual implementar políticas culturales e innovaciones educativas. Estamos trabajando en esta línea desde hace tres décadas, conscientes de la necesidad de implicarnos en los avances que promueven la convivencia y el equilibrio social. Hace cinco años creamos el museo online Museari para desarrollar proyectos y mejorar la situación de los colectivos minoritarios, utilizando el entorno online para coordinar esfuerzos y generar redes entre el profesorado.
\end{abstract}

PALABRAS CLAVE

Arte. Educación. Derechos Humanos. Museos. TIC.

RESUMO - Formação de professores do ensino fundamental defendendo a diversidade e inclusão. Memória de um caso de experiência docente através de Museari - Entre as possibilidades do ensino da arte destacam-se as questões da reivindicação social, especialmente a luta pela equidade e o respeito às minorias. Dentro dessa corrente socializadora, os avanços em gênero e diversidade são enquadrados. A luta pelos direitos humanos torna-se assim um lugar comum a partir do qual se implementam políticas culturais e inovações educacionais. Trabalhamos nessa linha há três décadas, conscientes da necessidade de nos envolvermos nos avanços que promovem a convivência e o equilíbrio social. Há cinco anos, criamos o museu on-line Museari para desenvolver projetos e melhorar a situação de grupos minoritários usando o ambiente on-line para coordenar esforços e gerar redes entre os professores.

PALAVRAS-CHAVE

Arte. Educação. Direitos Humanos. Museus. TIC.

ABSTRACT - Teacher training for Primary School defending diversity and inclusion. Memory of a case of teaching experience through Museari - Among the possibilities of Art Education we highlight the issues of social vindication, especially the struggle for equity and respect for minorities. Within this socializing line, advances in gender and diversity are framed. The struggle for human rights thus becomes a common place from which to implement cultural policies and educational innovations. We have been working on these issues for three decades, being aware of the need to get involved in the progress of coexistence and social balance. Five years ago we created the Museari online museum to develop projects and improve the situation of minority groups, using the online environment to coordinate efforts and generate networks among teachers.

\section{KEYWORDS}

Art. Education. Human Rights. Museums. ICT.

1 Este trabajo forma parte del proyecto de investigación "Arteari. Arte y diseño para entornos educativos libres de homofobia y transfobia" referencia UV-INV-AE18-779907 de la Convocatoria de Ayudas para Acciones Especiales de Investigación 2018 del Vicerectorado de Investigación de la Universitat de València. 


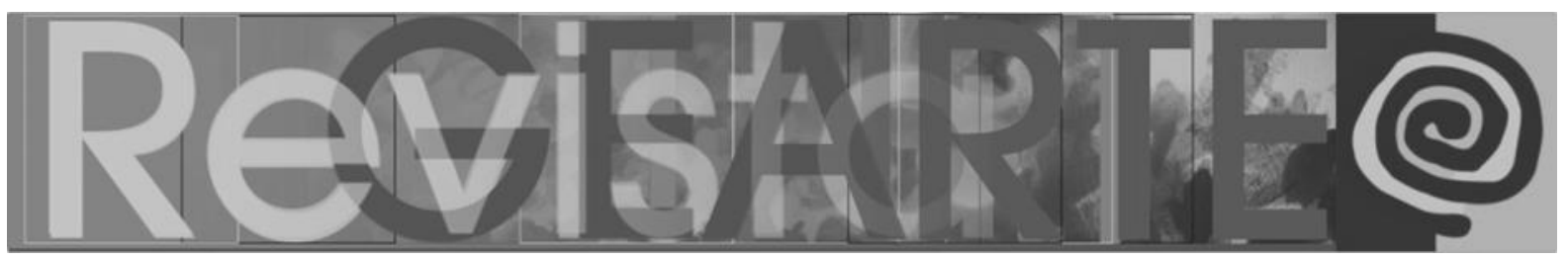

\section{Introducción}

Somos muchas y muchos docentes quienes desde hace décadas intentamos mejorar el papel de la educación en artes, insistiendo en cuestiones de reivindicación social. Pensamos que una de las mayores preocupaciones entre profesionales de la educación en artes es la lucha por la equidad y el respeto hacia las minorías. Dentro de esta corriente socializadora de la educación en artes se enmarcan los avances en materia de género y diversidad. Junto a los planteamientos que provienen de los feminismos emergen también las teorías y prácticas que proceden del activismo LGTB. La lucha por los derechos humanos se convierte, de este modo, en un lugar común desde el cual implementar tanto las políticas culturales como las innovaciones educativas. Conscientes de la necesidad de implicarnos en estos avances que promueven la convivencia y el equilibrio social, se creó Museari, un museo online en el que se desarrollan proyectos pensados para mejorar la situación de los colectivos LGTB, tanto del alumnado como del profesorado. Museari impulsa y coordina actividades a través del arte, la historia y la educación. Inspirado en la tradición académica y la cultura del respeto. El proyecto Museari utiliza las posibilidades que ofrece el ciberespacio para coordinar esfuerzos y posibilitar redes especialmente entre el profesorado, defendiendo el derecho a la diversidad. El entorno online permite promover artistas a nivel internacional, celebrando la educación en diversidad desde las artes, sin barreras.

Queremos incorporar aquí un acercamiento a la realidad que afecta a un caso personal de profesional que trabaja en educación artística desde hace décadas, con el fin de recuperar la realidad de esta lucha. Esta persona inició su andadura docente en el siglo XX, y sigue manteniendo el mismo espíritu combativo y rebelde con el que inició su carrera. Las metodologías basadas en narrativas personales y en las denominadas autonarrativas descriptivas nos ayudan a concretar el presente estudio (HERNÁNDEZ; SANCHO; RIVAS, 2011). Deseamos al mismo tiempo empoderarnos desde el entorno online, ya que el actual alumnado universitario está muy pendiente de este medio de transmisión de información y conocimiento. Por ello introducimos las 


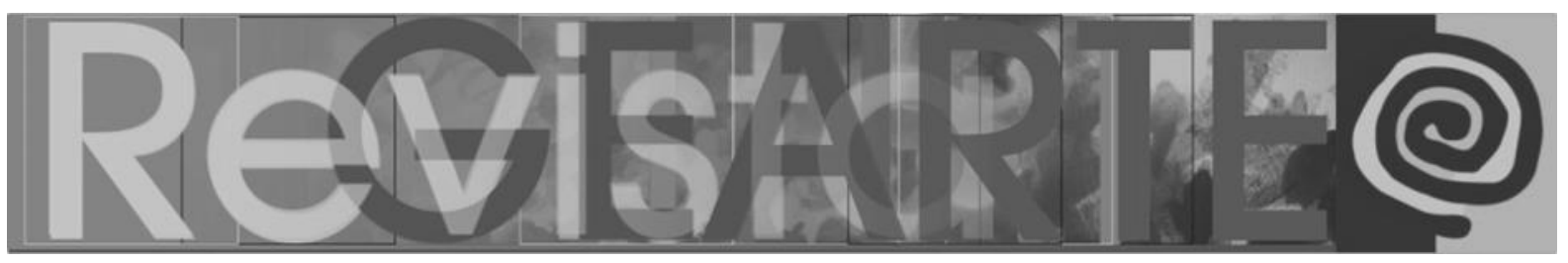

posibilidades que genera un museo online, que permite al profesorado adentrarse en las realidades diversas desde la creación artística contemporánea. El hecho de formar a futuros docentes de primaria supone acercarles a esta realidad diversa de modo que no se sigan ocultando los logros nivel educativo y de enseñanza de las artes visuales que tanto deben a las culturas LGTB.

Entre las características que definen el siglo $\mathrm{XXI}$ en materia de recepción estética y disfrute de las artes destacamos la presencia de las otredades (discursos creativos ajenos al heteropatriarcado) y la levedad en la transmisión comunicativa popular (fuerte impacto de la dimensión virtual y de los accesos tecnológicos por parte de públicos masivos). Enmarcados en esta situación, que es otra y es leve, observamos que son de nuevo las grandes multinacionales de la información y la comunicación quienes compiten por reestructurar las novedades en base a criterios básicamente comerciales y de calado economicista. Frente a esta omnipresencia de las empresas globales, se alzan voces peculiares que nos devuelven el entusiasmo y que proponen escenarios mucho más alternativos, y desde luego más comprometidos con las problemáticas sociales. En esta línea de creación de entornos culturales innovadores nació Museari, un museo online que defiende los derechos humanos desde la perspectiva de la diversidad sexual y de género. Museari se ha convertido en un espacio accesible, peculiar, curioso, activista, un entorno apto para generar reflexiones estéticas y educativas. Museari es una entidad sin ánimo de lucro que defiende los derechos humanos, que difunde las acciones de los colectivos LGTB y que se acerca a docentes de todos los niveles educativos (infantil, primaria, secundaria, universidad) para ofrecer propuestas novedosas que ayuden al alumnado y al profesorado a introducir estas temáticas en sus clases.

\section{Las voces de las alteridades en arte y educación}

En las últimas décadas venimos asistiendo a una serie de rupturas y tránsitos que están reconfigurando los territorios del arte (PATIÑO, 2017), de la estética (LADDAGA, 2006), de la educación (SANCHO; HERNÁNDEZ; RIVERA, 2016), y por 


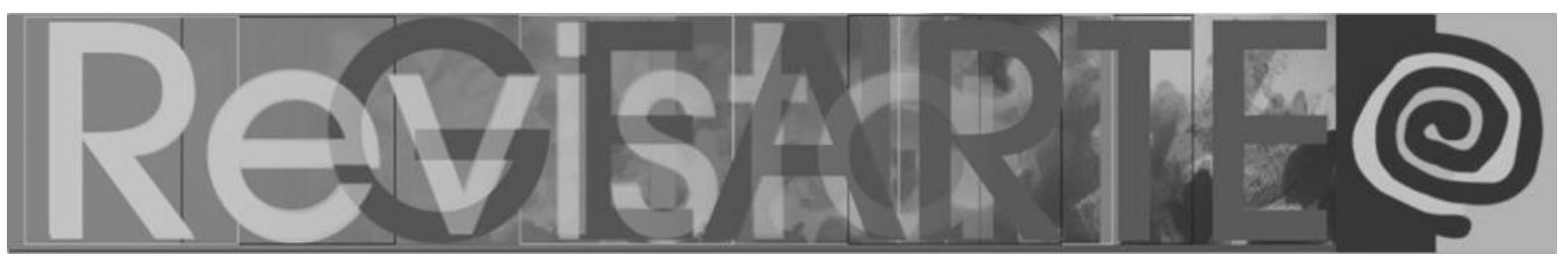

supuesto de la educación artística (HUERTA, 2017). Hemos pasado de un modelo en el que predominaba el rol del artista creador hacia una nueva realidad en la que urge atender el papel de los públicos usuarios y comprometidos. Esto ha provocado una tendencia hacia la reconversión de nuestros intereses, especialmente para quienes se dedican a la educación artística. Creemos que sucede algo similar en lo relativo a comportamientos ideológicos y políticos. Las certezas de la modernidad propias del siglo XX nos empujaban hacia polaridades y distanciamientos. Nuestro acercamiento a los usos culturales siempre estuvo muy mediado por las reflexiones semiológicas (BARTHES, 1982). Sin embargo, el panorama rizomático ha resquebrajado los postulados anteriores, de manera que los flujos cambiantes del momento actual nos sitúan en incertidumbres líquidas más propias de un cierto malestar permanente. Se trata de un estado donde predomina la levedad, tal y como había preconizado Ítalo Calvino con sus Lecciones Americanas (CALVINO, 1995). Poco después fueron Deleuze y Guattari quienes insistieron en la volatilidad de los pronósticos, ya que desde las miradas anteriores propias del binarismo moderno únicamente se atendía a la polaridad y la duplicidad: "Ni qué decir tiene que este pensamiento jamás ha entendido la multiplicidad: para llegar a dos, según un método espiritual, necesita presuponer una fuerte unidad principal" (DELEUZE; GUATTARI, 2004, p. 11). Pese a las tendencias más líquidas en las que estamos instalados (según Zigmut Bauman) lo cierto es que las tensiones continúan, y esto es debido en parte al modelo de economía neoliberal en la que nos encontramos inmersos. También en la vertiente de la comunicación impera lo que Itamar Even-Zohar describió como "polisistemas" (EVEN-ZOHAR, 1990). En cualquier caso, las alteridades están impulsando nuevas lecturas del mundo, y tenemos que celebrar el empuje de miradas que provienen de los feminismos, de la diversidad LGTBIQ, de las posiciones afroamericanas, y de todos los pensamientos otros.

Al revisar los espacios de las diversidades LGTBIQ, observamos que una de las voces más rompedoras es sin duda el engranaje queer. El propio concepto queer lo podemos entender como un territorio de tensión donde se dan discursos y prácticas que se posicionan contra las narrativas dominantes, narrativas que son habitualmente 


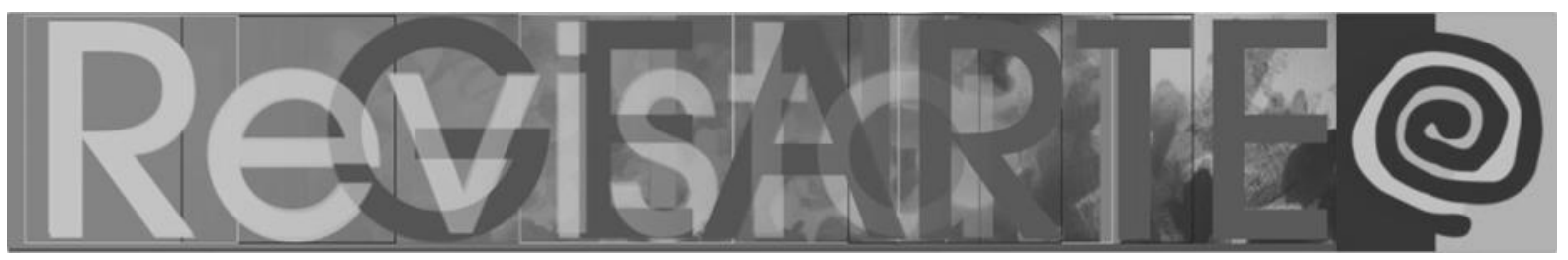

de cariz blanco, hetero, cis y monógamo, modelos donde se sitúan personas que han construido su subjetividad a través de un proceso identitario, reconociendo y trabajando sus privilegios. Lo queer supone un total rechazo al régimen normativo en diferentes dimensiones, por ello propone la interseccionalidad de la lucha y la ruptura con toda norma que presione sobre nuestros cuerpos por motivos de clase, raza, género, sexualidad o corporalidad. La transgresión ha sido y sigue siendo la marca identificadora de las otredades. Dentro del espectro LGTB podemos encontrar voces singulares, incluso distantes. Estamos asistiendo a una reverberación mediática de la visibilidad de estos colectivos diversos, lo cual enriquece el panorama visual de estas nuevas realidades. Un ejemplo sencillo que evidencia esta mayor visibilidad sería la profusión del imaginario de la diversidad sexual: se han popularizado elementos gráficos del elenco LGTB como la bandera multicolor o el triángulo rosa, se han instituido manifestaciones como las marchas del Orgullo, y tanto en el cine como en la televisión o en la literatura escrita se prodigan los personajes y las temáticas alusivas. Por otro lado, la mayoría de avances en materia de derechos legales y de progreso social que venimos observando en los logros del colectivo LGTB atienden a unas políticas de igualdad que responden a criterios de visibilidad y mejora de la calidad de vida de las personas (MORENO y PUCHE, 2013). Pero también existen retrocesos espectaculares en países donde se había logrado avanzar. 


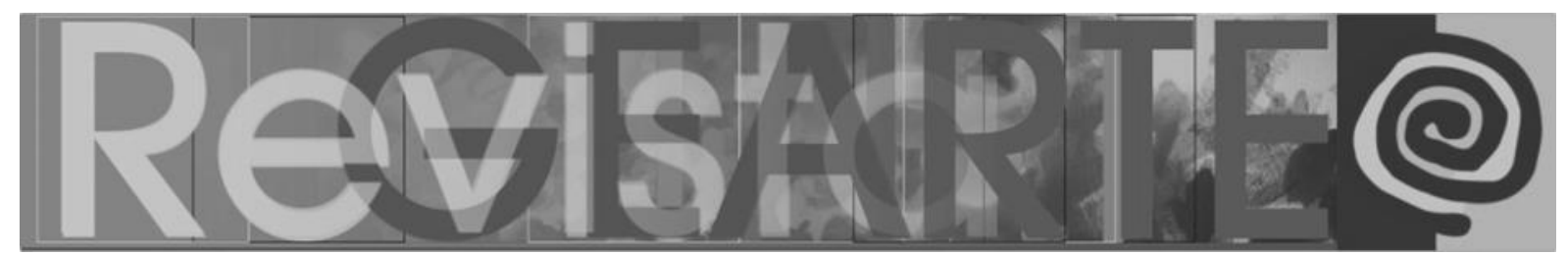

Figura 1 - "Mans d'estimar 2". Fotografía de Xavier Mollá para Museari

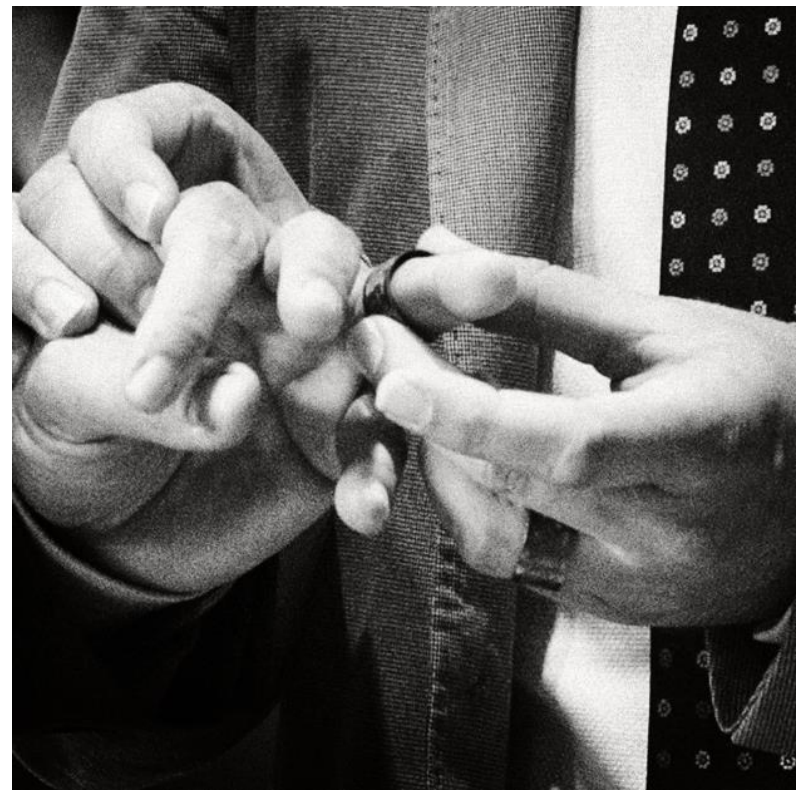

Fuente: https://www.researchgate.net/figure/Figura-1-Mans-d-estimar-5-Fotografia-de-XavierMolla_fig1_322159396

En la Figura 1 vemos las manos de dos personas que se casan, y que acreditan su enlace con unas alianzas. Esta imagen nos sirve en clase de magisterio para tratar el tema del matrimonio igualitario. El artista nos sitúa en un peculiar álbum de fotos de boda, ya que los que se casan son dos hombres, y en la imagen se ponen los anillos. La peculiaridad de las imágenes cuando se trata de diversidad es que transmiten los sentimientos, con abrazos y gestos de cariño. No hay poses, la gente que asistió a la boda no sabía que se estaban haciendo las fotografías para un reportaje. Se utiliza el esquema tradicional "álbum de fotos de boda" para relanzar un mensaje mucho más abierto y actual. El derecho al matrimonio de todas las personas es un logro de la lucha del movimiento LGTB.

Como docentes vivimos muy de cerca esta cuestión, ya que nuestro matrimonio fue entre dos personas del mismo sexo. Resulta fundamental hablar abiertamente al alumnado de estas cuestiones. El mundo educativo está atendiendo también estas necesidades y urgencias que son propias del nuevo emplazamiento liviano y diverso (HAMLIN; FUSARO, 2018). Vamos revisando los papeles del alumnado y el profesorado en el marco de las relaciones académicas (ROLLING, 2017). Se investiga 


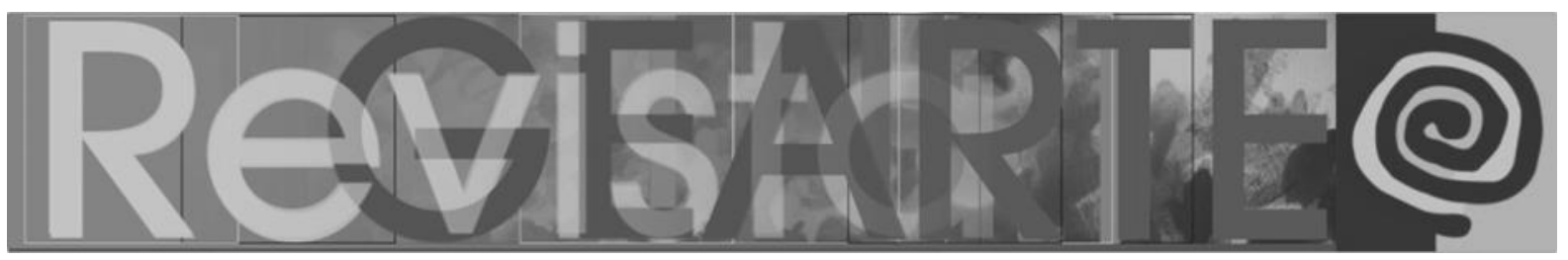

sobre las posibilidades de mejorar los entornos educativos en base a criterios donde no primen únicamente los intereses económicos, y donde se puedan articular escenarios más generosos e integradores (KRAHE, 2017). El papel de los implicados en la investigación educativa se desplaza hacia los intereses de las personas y los colectivos, de manera que el currículum deja de ser la razón última de las relaciones entre alumnado y profesorado (HUERTA; ALONSO-SANZ, 2017). Ahora nos preocupan más los sentimientos y las emociones, algo que hasta hace bien poco no se había tomado en serio por parte de los responsables educativos. Nos hemos marcado nuevas direcciones y hemos dado paso a una gama más amplia de matices (PLANELLA, 2014). El cuerpo, los deseos, las pulsiones y la libertad constituyen elementos fundamentales para gestionar una buena mejora de las condiciones de vida de las personas (FOUCAULT, 1998). La forma de gestionar estas nuevas visiones de lo corporal (BUTLER, 2006) han de resultar familiares al profesorado, especialmente a los maestros de primaria y a los docentes de secundaria. Si formamos desde la universidad a estos futuros profesionales de la educación, debemos introducir las temáticas que están cambiando y mejorando el panorama de los derechos humanos en materia de diversidad. Todas las iniciativas han de basarse en el respeto y la coherencia. Los hechos personales que nos afectan como profesores también forman parte del currículum que debemos transmitir al futuro profesorado de primaria (HUERTA, 2019). Cuando recuerdo que en la infancia padecí bullying homofóbico, y que a lo largo de toda mi vida he tenido que combatir constantemente los ataques contra las personas que somos diversas, reflexiono y me reafirmo en la necesidad de transmitir a mi alumnado estas cuestiones, que tanto sufrimiento provocan a personas inocentes.

\section{La defensa de los derechos humanos desde los colectivos LGTB}

La evolución de los logros conseguidos por los colectivos LGTB ha tenido numerosos momentos históricos destacados. La reyerta entre la policía de Nueva York y los clientes del pub Stonewall Inn el 28 de junio de 1969 dio paso a una nueva época marcada por la lucha por los derechos, por la visibilidad, y por la proliferación del 


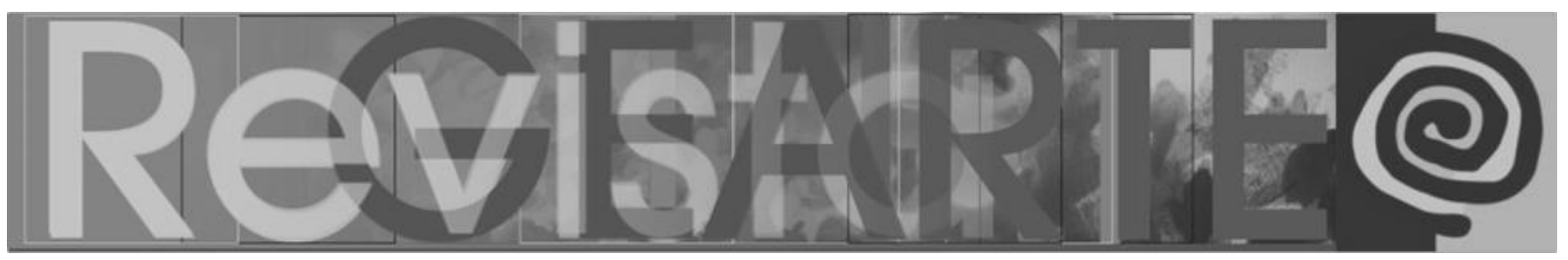

asociacionismo a nivel internacional. En parte debido la presión que iniciaban entonces los colectivos a favor de los derechos humanos, en 1973 la Asociación Norteamericana de Psiquiatría retiró a la homosexualidad la condición de trastorno en el Manual Diagnóstico y Estadístico de Trastornos Mentales (DSM-II). La gravedad y transcendencia de la pandemia del SIDA durante las décadas de 1980 y 1990 tuvo como consecuencia un nuevo impulso en positivo para que se atendiesen los derechos de las personas afectadas, convirtiendo lo que inicialmente había sido una agresión brutal hacia el colectivo homosexual en un logro por la visibilidad de estas problemáticas. Viví todo esto muy de cerca, siendo ya profesional de la educación artística.

Fue en 1990 cuando la Organización Mundial de la Salud (OMS) eliminaba definitivamente la homosexualidad de la Clasificación Estadística Internacional de Enfermedades. En 2006 se aprobó en España en matrimonio entre personas del mismo sexo, dentro de una espiral de normalización que ha llevado a la mayoría de parlamentos de los países occidentales a aprobar el matrimonio igualitario. A pesar de todos estos avances que afectan a la medicina, a la legislación y a todo lo que supone una incidencia en la vida de las personas, no podemos olvidar que tanto los prejuicios sociales (homofobia imperante) como los convencionalismos religiosos (castigo a la disidencia) siguen manifestando su poder en contra de los derechos de la ciudadanía diversa. En cualquier caso, las leyes deben redactarse en favor de las minorías oprimidas y de los colectivos más desprotegidos (COUNCIL OF EUROPE, 2011). 


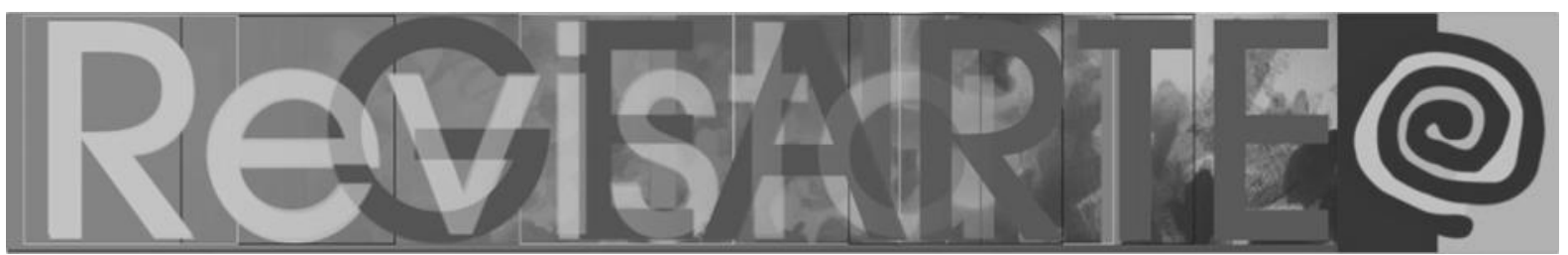

Figura 2 - "Sudamérica". Montaje. Obra de Álex Meza expuesta en Museari

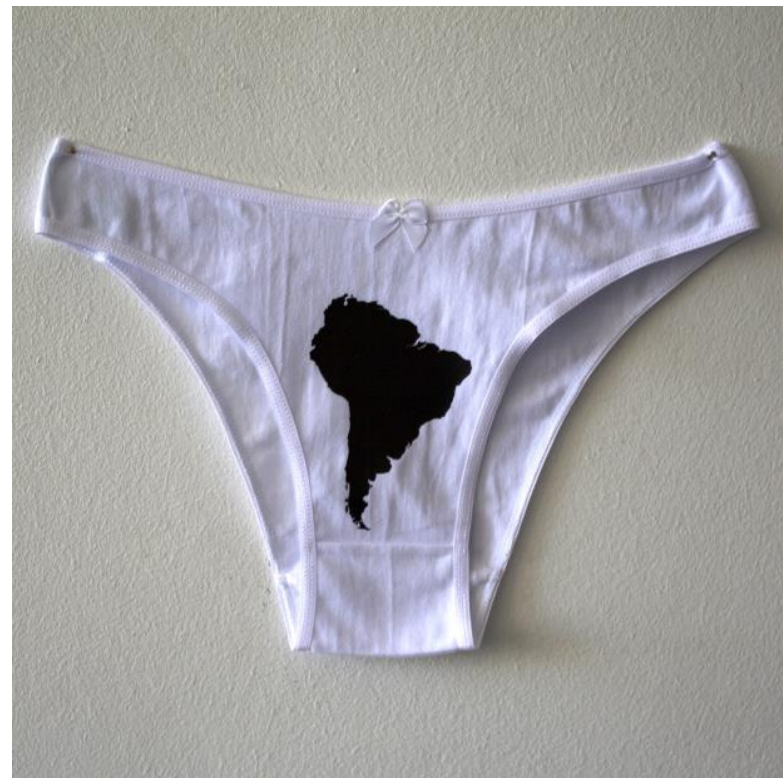

Fuente: https://www.museari.com/portfolio_page/alex-meza/

El artista chileno Álex Meza evidencia con su imagen (Figura 2) el desequilibrio del sistema educativo chileno, la falta de equidad y la problemática constante de las desigualdades de género que se transmite a los valores del propio territorio colonizado. También alude a la problemática del bullying, ya que el acoso escolar entre alumnado diverso sigue siendo preocupante. Este tipo de obras nos permite hablar en clase de cuestiones vinculadas al feminismo y a la descolonización cultural, económica y política, sin perder nunca de vista el papel de las artes (AMARAL, 2019). La propia autora del artículo nos recuerda que "Vivemos em uma sociedade com comportamentos padronizados, normatizados, cujos espaços são considerados dos homens, mesmo porque quem dita as regras que nesses espaços circulam e neles se mantém são os homens" (AMARAL, 2019, p. 48). 


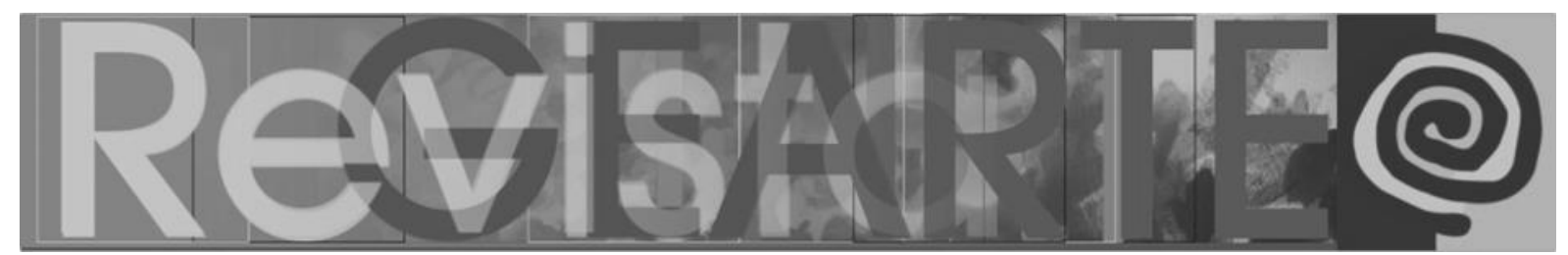

Figura 3 - "Ferida de temps". Obra de Nora Ancarola expuesta en Museari

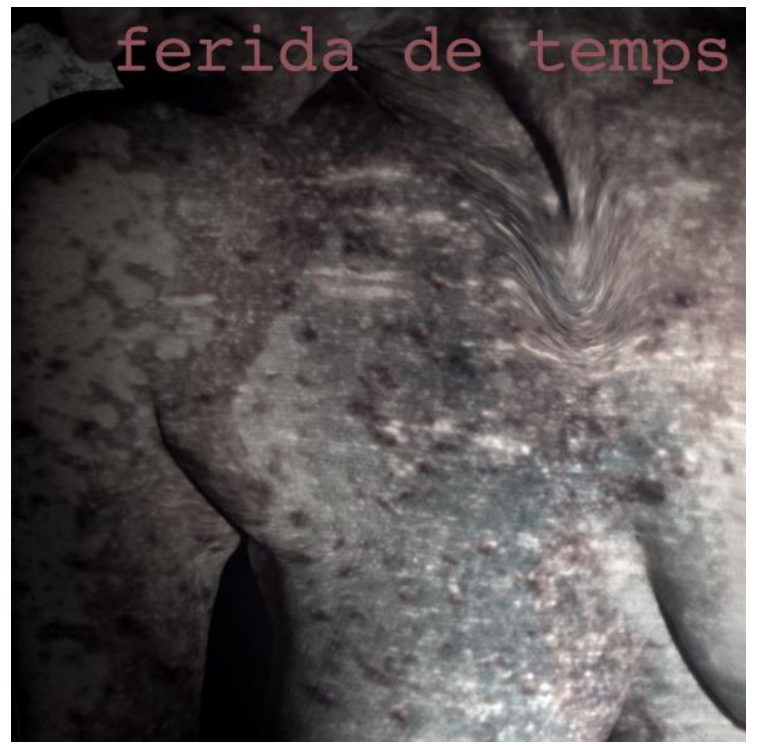

Fuente: https://www.museari.com/portfolio_page/nora-ancarola/

Más allá de nuestra condición de hombres o mujeres, debemos enfrentarnos al problema del machismo, una herencia que afecta tanto a mujeres como a colectivos de la diversidad sexual, y es incluso perjudicial para desarrollar de forma aceptable la propia masculinidad. La artista Nora Ancarola, de procedencia argentina pero afincada en Barcelona, utiliza su propio cuerpo para marcar las huellas del tiempo (Figura 3). La presión social y cultural que se ejerce sobre las mujeres en este sentido es mucho mayor, ya que el envejecimiento se enmarca en los procesos de desatención e invisibilidad. Pensemos en las mujeres mayores, y en su constante invisibilización social. El problema de la gerontofobia es otro aspecto que conviene inculcar al futuro profesorado de primaria. El respeto y el reconocimiento de la diversidad es algo que urge asumir y defender tanto cuando afecta a las mujeres como a las personas y colectivos homosexuales.

Cabe decir que en educación artística se han escuchado voces desde hace décadas alentando estos derechos y avances (FREEDMAN, 1994). Si las razones que venimos esgrimiendo apuntan hacia una mejora dentro del panorama global, especialmente en lo referido al ámbito médico, a la situación legislativa y el conjunto social, hemos de reconocer que en el entorno educativo todavía sigue existiendo un 


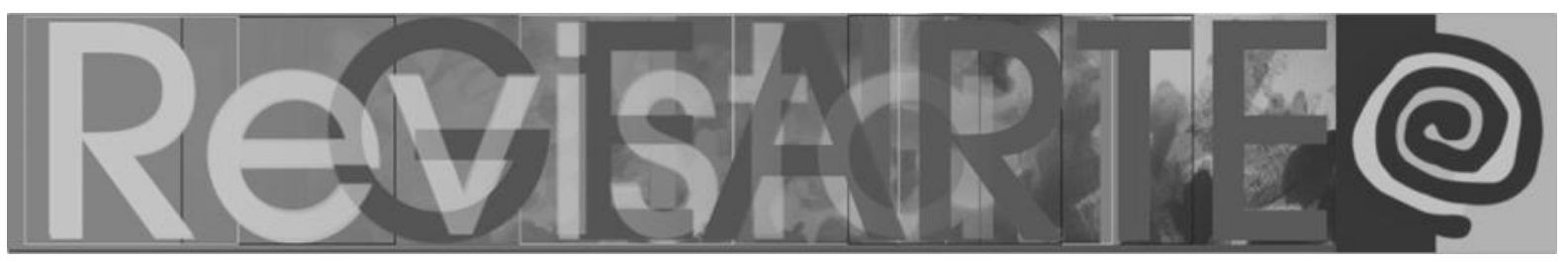

cierto temor a expresar libremente la orientación sexual diversa (TIN, 2012). Profesorado y alumnado con diferentes opciones sexuales o de género sigue padeciendo el rechazo, lo cual provoca un silencio claustrofóbico y empaña cualquier intento de normalizar la situación tanto a nivel social (ERIBON, 2014) como educativo (PICHARDO, 2015).

\section{Alimentar desde lo personal el paisaje cultural de los nuevos museos online}

Las nuevas realidades que ha propiciado el entorno online están replanteando muchas cuestiones que hasta hace bien poco parecían inalterables e inamovibles. Un ejemplo de ello es la propia esencia del concepto de patrimonio (HUERTA; CALLE, 2013) y más concretamente la configuración del museo como institución. Atendiendo a la normativa ICOM (International Council of Museums) partimos de la definición de museo como una "institución permanente, sin fines de lucro, al servicio de la sociedad y abierta al público, que adquiere, conserva, estudia, expone y difunde el patrimonio material e inmaterial de la humanidad y su ambiente con fines de estudio, educación y recreo". Esta definición sigue vigente desde que en el Congreso de Viena de 2007 se aprobase por los comisionados de todos los países integrantes, pendiente de su actualización en 2019. Para obtener una calificación positiva por parte de ICOM, los museos deben atender todos los aspectos referidos: adquisición, conservación, estudio, educación y recreo. A nosotros nos interesa reforzar el papel educativo de los museos. El museo debe inspirar encuentros como una institución aliada del trabajo educativo y de los profesionales de la docencia (HUERTA, 2010). En el caso de los museos de arte disponemos, además, de imágenes y recursos que servirán para atender a múltiples cuestiones vinculadas con la cultura y los progresos de la humanidad. Algo similar ocurre con el lenguaje del cine (HUERTA; ALONSO-SANZ; RAMON, 2019). No perdamos de vista que uno de los elementos más reproducidos en las obras de arte es, precisamente, el cuerpo humano. $Y$ el cuerpo en disputa es el elemento clave de las cuestiones que afectan al deseo, a la mirada y a la representación visual de lo carnal. Estos temas forman parte esencial de nuestras clases de formación del profesorado de primaria, donde analizamos desde el trabajo 


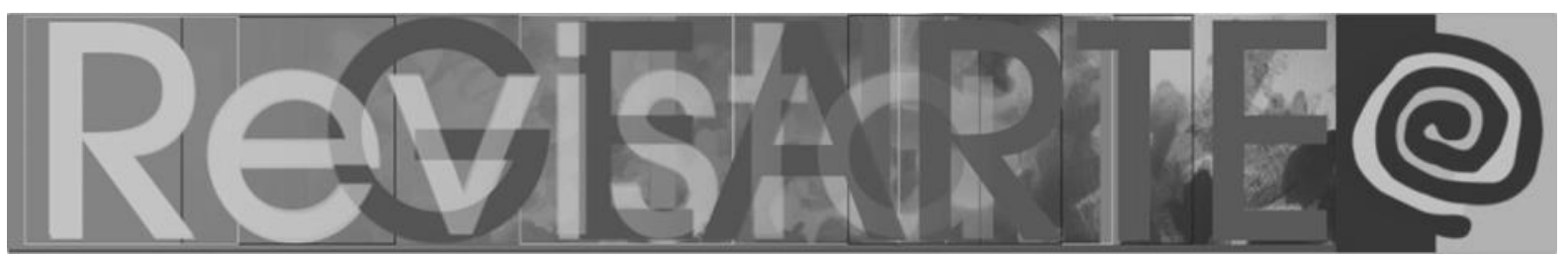

por proyectos cuestiones como: la muerte, el cuerpo, la diversidad, el miedo, la memoria. Si lo observamos como una trayectoria histórica de la mirada, los desnudos masculinos y femeninos que atraviesan la historia del arte y que actualmente inundan el cine, la televisión y los videojuegos, son en realidad una constante que podríamos entender como un motivo visual (BALLÓ, 2000). Recorrer la historia de la representación de San Sebastián en los numerosos ejemplos de los museos del mundo supone entender la mirada del arte hacia el cuerpo humano en diferentes épocas y tradiciones. Incluso analizar aquellos elementos invisibilizados por parte de los museos puede suponer un memorable ejercicio de aproximación a los tabúes tradicionales (FROST, 2007).

Figura 4 - "Elogio de la pluma". Fotografía de Pepe Miralles expuesta en Museari

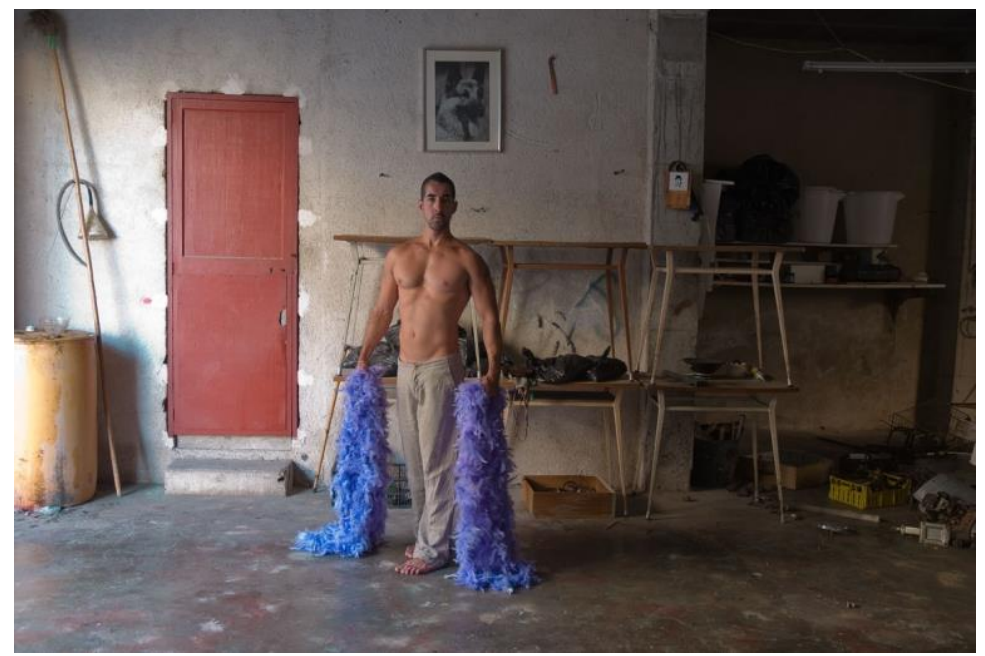

Fuente: http://www.pepemiralles.com/elogio-de-la-pluma-2/

El artista Pepe Miralles nos ofrece una imagen tomada en un lugar en el que se practica el cruising (Figura 4). Un joven lleva unas plumas y posa semidesnudo ante la cámara. Ante la represión de la "pluma", se abre una verdadera encrucijada de caminos, donde las opciones son muchas, pero la verdadera elección supone aceptarse a sí mismo, evitado así el sufrimiento que generan las propias cárceles personales. Debemos inculcar a nuestro alumnado, futuros maestros y futuras maestras de primaria, el respeto hacia todas las opciones. La burla tradicional contra los hombres por considerarles "afeminados", o el rechazo social a las mujeres por culparlas de "machos", es una trampa en la que llevamos inmersos demasiado tiempo. 


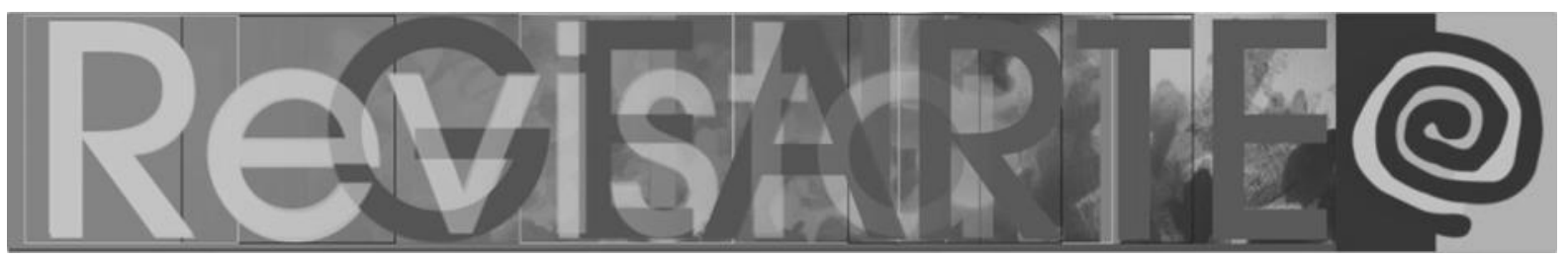

La opción sexual, el sexo, así como las decisiones identitarias, corresponden a cada persona, y no a quienes le puedan juzgar desde afuera (COSTA, 2019).

Gracias a nuestra experiencia docente durante décadas, y a nuestro interés constante por la educación en museos, hemos podido revisar los aspectos tradicionales de la relación entre el museo y las opciones educativas, teniendo en cuenta que en la actualidad muchos museos ya no se sustentan en una realidad geográfica, sino que forman parte del entorno online. Se trata de museos que existen en internet como entidades que mantienen su estrategia dentro de los parámetros de la realidad virtual. Estos museos también cumplen con los requisitos del concepto acuñado por ICOM, pero a diferencia de los museos convencionales, no existe un espacio geográfico en el que ubicarlos, sino que optan por ofrecer sus servicios a través de la red. Quisiera aclarar aquí que no estamos hablando de las "versiones digitales" de los museos ya existentes, ni tampoco de las aplicaciones en red que algunas instituciones convencionales han adaptado de sus colecciones. Nos referimos a museos que han nacido desde una perspectiva digital y que tienen su actividad básicamente en el entorno virtual. Un caso que conocemos muy bien por nuestra implicación directa es Museari Museu de l'Imaginari. Hablamos de un entorno online que organiza sus activos a partir de la conexión digital con sus visitantes y usuarios.

\section{La creación de Museari}

En julio de 2015 nació Museari Museu de l'Imaginari como un nuevo concepto de museo que parte de la iniciativa profesorado universitario. El nacimiento del museo está vinculado al activismo de este profesorado, y cuya presencia atiende a la necesidad de visibilizar su situación para ayudar a las personas que continúan teniendo miedo a expresar sus sentimientos. Se trata de un museo online que ofrece la posibilidad de acceder a sus contenidos de manera gratuita. Pretende formar e informar a sus visitantes en la línea de trabajo y difusión que plantea ICOM. De hecho, la presentación de Museari fue en las sesiones del Congreso Internacional de CECA ICOM celebrado en Washington del 16 al 21 de septiembre de 2015 con el título 


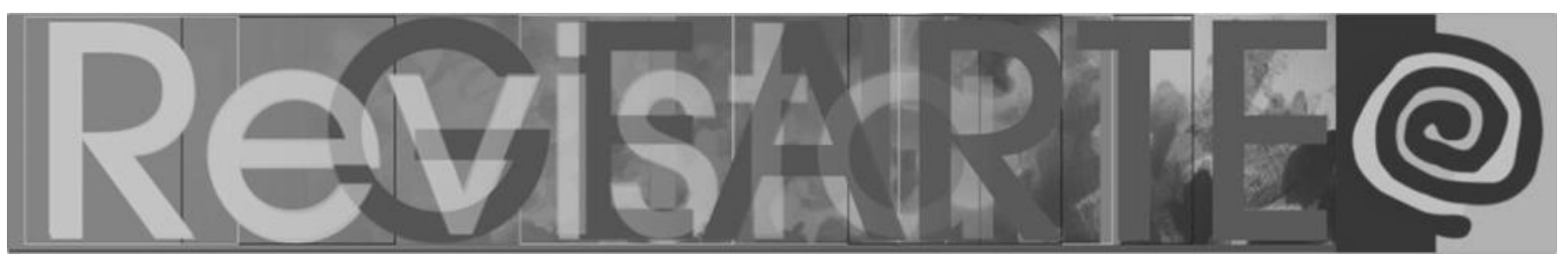

"Museum Education and Accessibility: Bridging the Gaps", donde se presentó la ponencia seleccionada "Museari. An Online Museum About Sexual Diversity". Y es que entre los contenidos definitorios del museo destaca la defensa de los derechos humanos, especialmente atendiendo a la diversidad sexual, y apoyando las reivindicaciones de los colectivos LGTB. Es también un espacio de investigación sobre educación artística e historia.

Figura 5 - "Churro, mediamanga, mangaentera". Obra de Moisés Mahiques en Museari

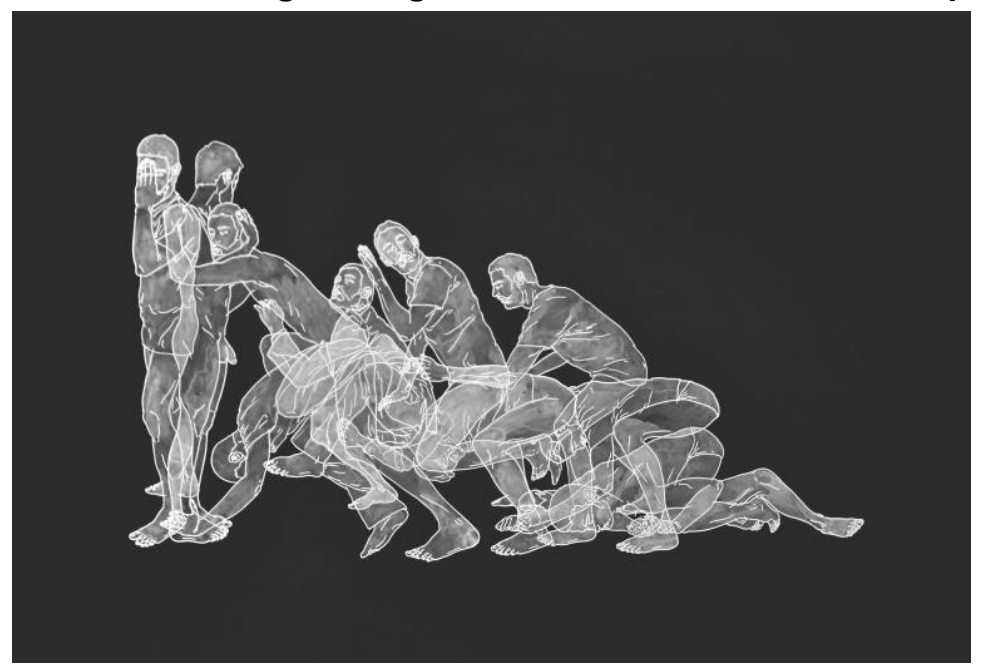

Fuente: https://valenciaplaza.com/museari-el-museo-virtual-que-amenaza-con-cambiar-la-forma-depromocionar-el-arte

Los cuerpos dibujados por el artista Moisés Mahiques están sometidos a una maraña de relaciones en las que nacen y mueren constantemente deseos, pasiones y encuentros fortuitos (Figura 5). Durante siglos han estado prohibidas las relaciones sexuales que fuesen ajenas a la reproducción. Esta tradición impide que se conozcan muchas de las posibilidades que transmite el propio cuerpo. En realidad, el cuerpo acaba siendo un campo de batalla, como señala la artista Barbara Kruger en una de sus obras más celebradas.

Como creadores de Museari exponemos a través de las salas del museo nuestros planteamientos, así como los objetivos y los intereses que predominan en la historia fundacional de esta institución virtual de ámbito cultural y educativo. Al no existir iniciativas anteriores que sirvan de referente, este museo adopta una línea de 


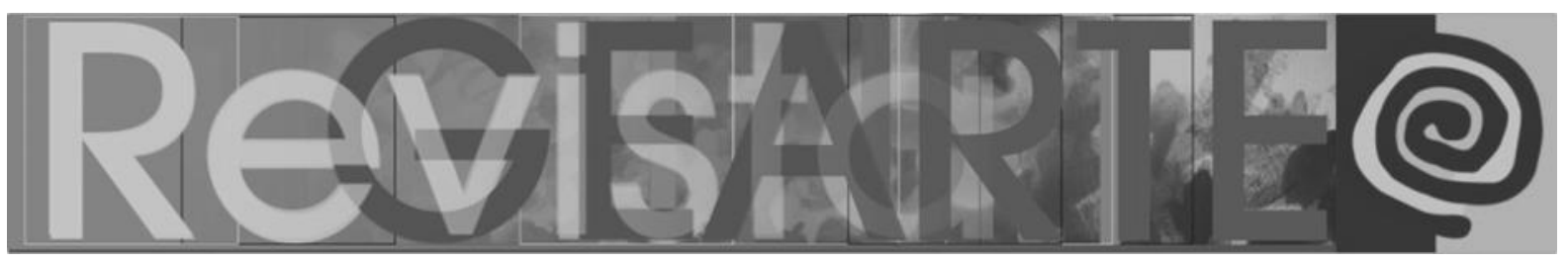

trabajo particular y original. Se trata de una web con diferentes dominios adquiridos, por lo que se consigue un elevado escenario de asistencia por parte de los buscadores generalistas, especialmente en el ubicuo Google. Otra peculiaridad que define Museari es su gran capacidad de repercusión en las redes sociales, ya que está presente con perfil propio en Facebook, en Twitter, en Academia.edu y también en Instagram. El modelo combina colección permanente, exposiciones temporales, noticias, sugerencias, interactividad con los públicos y acciones educativas para centros docentes.

El escenario social y político en el que nos movemos en los países occidentales ha permitido conseguir logros importantes en lo relativo a derechos de grupos minoritarios. Las democracias europeas y americanas están dando muestras palpables de avances en materia legal y asistencial hacia los colectivos LGTB. Somos conscientes de que entre todos estamos consiguiendo que se superen muchos problemas que hasta hace bien poco parecían insalvables. Incluso a nivel cultural se está asumiendo el importante papel del colectivo en las parcelas de los saberes creativos (LORD; MEYER, 2013). Y, sin embargo, no podemos perder de vista que lo conseguido puede que no se vaya a mantener siempre. Es por ello que la lucha por los derechos humanos debe continuar firme, y no podemos confiar en la perennidad de los logros, ya que constantemente están en peligro los avances alcanzados.

Vamos a seguir esforzándonos, y sobre todo hemos que lograr que lleguen también los derechos para aquellas personas que en sus respectivos países siguen siendo perseguidas, vejadas, humilladas, o incluso asesinadas a causa de su orientación sexual. No podemos permitir que continúe habiendo tanta gente en el mundo sufriendo por algo que es en realidad un derecho: defender y preservar su orientación sexual. Esto supone asumir una particular forma de vivir los propios sentimientos y deseos. Debemos erradicar la homofobia, la transfobia, la lesfobia, la bifobia, y todos los odios que atentan contra las diferentes opciones de la diversidad sexual (ROBINSON, 2014). Desde Museari generamos acciones y nos esforzarnos por conseguir que en todo el mundo se respeten los legítimos derechos de las 


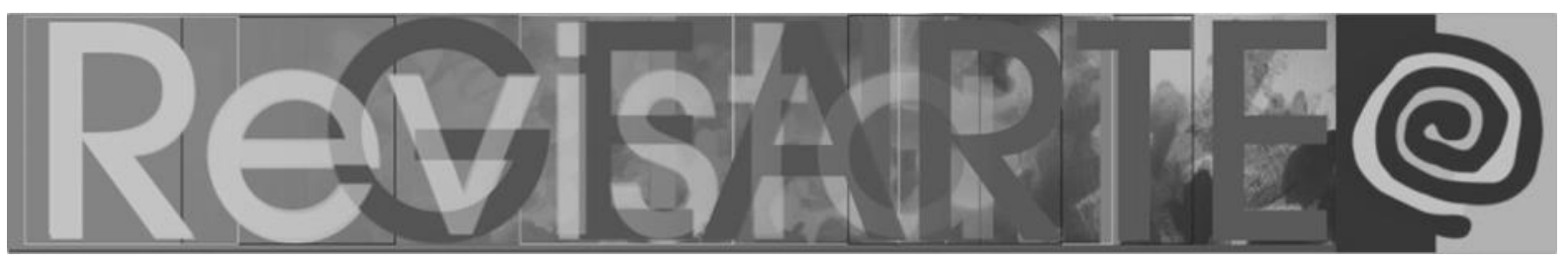

personas cuando eligen cómo llevar su vida en función de su propia orientación sexual y de género. Se ha avanzado mucho desde los acontecimientos de Stonewall Inn, pero todavía queda un largo camino por recorrer para lograr una verdadera normalización de la situación, especialmente en el terreno de lo educativo. Los prejuicios religiosos y la presencia obcecada del machismo recalcitrante continúan frenando muchas oportunidades de mejora (UNESCO, 2012). Pese a todas las dificultades, observamos que progresivamente aumentan los logros sociales, legales, políticos y culturales en el terreno de la defensa de los derechos humanos y de la diversidad sexual.

\section{La trayectoria de Museari en el marco de una geografía líquida}

Al tratarse de un escenario innovador, la apuesta es doblemente arriesgada. Por un lado nos mantenemos en una posición que sigue los esquemas universalmente aceptados, ya que Museari es un museo online, una institución permanente sin fines de lucro al servicio de la sociedad y abierta al público, que adquiere, conserva, estudia, expone y difunde su patrimonio (PANCIROLI, 2016). Por otra parte, arriesgamos a todos los niveles en tanto que los objetivos principales de Museari son la promoción de la educación artística y de la historia como instrumentos fundamentales para la defensa de los derechos humanos, incidiendo en el respeto a la diversidad sexual. Forman parte de la colección permanente las obras singulares de numerosos artistas que han cedido sus piezas a Museari, contribuyendo a su puesta en valor, catalogación, estudio y divulgación. También se potencia la producción artística, humanista y científica de aquellos autores que traten sobre las diferentes temáticas prioritarias del museo (ALIAGA, 2004). Cada año se diseña un programa de actividades. En dicha programación destacan las 12 exposiciones temporales que se inauguran el día 17 de cada mes, muestras que están compuestas por aquellas obras elegidas por cada artista participante. En las ilustraciones puede comprobarse la calidad de las piezas expuestas y el alto nivel de los artistas que participan con sus obras en las exposiciones temporales del museo. 


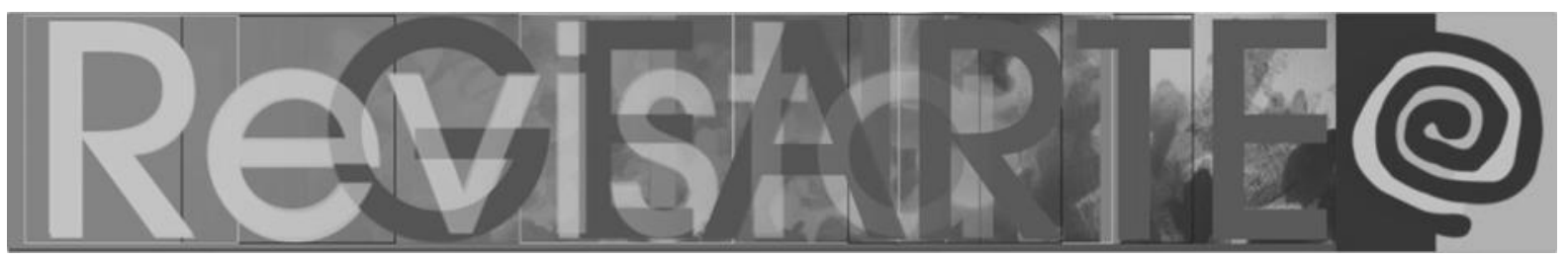

En la exposición de la escultura Maribel Domenech podemos ver las obras de esta artista que con sus telas cosidas con materiales industriales metálicos y plásticos nos plantea la infamia de la violencia machista. Sus fotografías e instalaciones hablan de las duras condiciones en las que viven muchas mujeres. Aquí el cuerpo fluye en muchos sentidos, se relaciona con el mundo de forma líquida, y promete descubrimientos más allá de los convencionalismos y estereotipos. La libertad es un instrumento vital de los cuerpos que desean. El arte construye caminos para alcanzar horizontes no imaginados. Por su parte, el reconocido artista Abel Azcona realiza acciones donde lleva su propio cuerpo al límite. En sus performances mantiene relaciones con las personas que participan, desafiando de este modo las normas establecidas incluso en el terreno del arte. Por su parte, los grabados de José Manuel Guillén hablan de la pasión de la juventud hacia lo enigmático y desconocido. Un joven mira un pez rojo mientras se zambulle en el agua. El arte permite una mirada más abierta y significativa de nuestros propios procesos de conocimiento. La curiosidad es un camino lleno de sorpresas. Las prohibiciones forman parte del lenguaje del poder.

Tras varios años de andadura, ya son centenares las obras de arte que tienen a su alcance los usuarios para visitar en Museari, pensadas especialmente para facilitar las tareas al profesorado, y evidentemente también para la formación de dicho profesorado. Estamos hablando de un museo online que apuesta por el encuentro con el resto de museos del mundo, integrándose en la red internacional vinculada a ICOM UNESCO (HUERTA; NAVARRO, 2016). El museo cuenta con un Comité Científico Asesor integrado por profesionales del mundo de las artes, las humanidades y las ciencias sociales. Dicho comité propone las candidaturas, en sus diferentes modalidades, para los Premios Museari, una convocatoria anual que distingue a las personas y las entidades que hayan destacado por sus acciones en el terreno de las temáticas prioritarias del museo. Los derechos humanos son de importancia primordial, $y$ al hablar abiertamente sobre reivindicaciones LGTB provocamos asimismo un ambiente distendido en el que aquellas personas que anteriormente se habían visto forzadas al silencio, ahora tienen la oportunidad de hablar y expresarse libremente. 


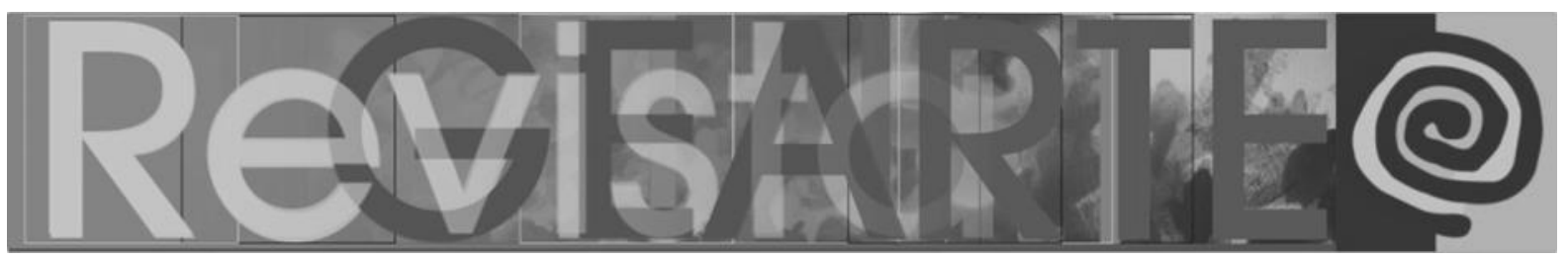

El derecho al libre desarrollo de la personalidad, a una vida digna y sin violencia, constituye uno de los principales derechos humanos reconocidos internacionalmente (Art. 5, 12, 22 y 26 de la Declaración Universal de los Derechos Humanos). El derecho a la educación sin discriminación por orientación sexual o identidad de género se encuentra respaldado por los artículos 2, 28 y 29 de la Convención sobre los Derechos del Niño y en los Principios de Yogyakarta. Los artistas que exponen en Museari asumen todas estas premisas, y colaboran con sus creaciones a una verdadera transformación de la sociedad, intentando así superar la discriminación y la exclusión por homofobia y transfobia, realidades presentes en todas las sociedades, estigmas desafortunados que se reproducen también en los centros educativos. Es en el terreno de lo educativo donde Museari apuesta de manera decidida, incorporando acciones desde las artes y la educación artística.

\section{Educar en artes desde un entorno virtual}

Museari elabora materiales educativos vinculados a su colección permanente y a las exposiciones temporales, colaborando con otras instituciones en la programación de conferencias, mesas redondas, presentaciones, ediciones, estimulando así un mayor alcance para sus fines fundacionales (NAVARRO, 2019). En el apartado Museari Educa, que es uno de los menús principales de la web del museo, encontramos el subapartado Actividades. Es importante que el profesorado de infantil, primaria y secundaria cuente con materiales para llevar al aula las temáticas que afectan a los colectivos LGTB (NAVARRO, 2014). Entre las propuestas ofertadas podemos encontrar 21 actividades pensadas para asesorar al profesorado de Educación Primaria. Los docentes que deseen trabajar en sus clases disponen ahora de materiales que les llegan a través de internet. Este es un aliciente motivador, ya que son de fácil acceso (gratuitos, y siempre disponibles) para quienes quieran desarrollar este tipo de acciones en sus aulas. De este modo, el profesorado dispone tanto de las obras artísticas expuestas en el histórico del museo, como de las actividades pensadas para llevarlas a cabo en el aula. 


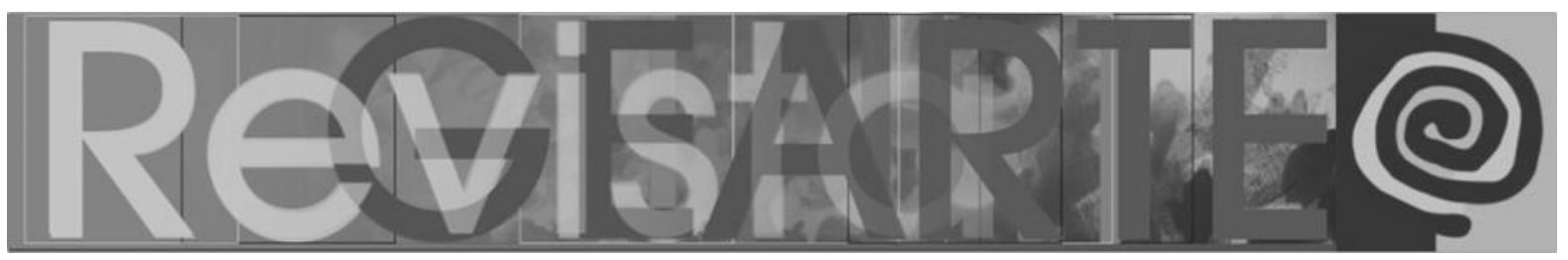

Si revisamos las 21 Propuestas contra el Bullying Homofóbico que se plantean en Museari Educa, encontraremos también las opiniones de sus creadores. Se trata de alumnado de Magisterio, que con su mirada joven y porosa han realizado estas actividades pensando en ofrecer al profesorado de Educación Primaria una serie de recursos para trabajar en el aula. La actividad que ofrece Laia consiste en ver "un vídeo en el que aparece un niño que tiene comportamientos distintos al resto de niños y por ello sufre bullying homofóbico. Se observa cómo es agredido verbalmente y maltratado hasta por su propia familia porque no aceptan como es su hijo". Por su parte Yolanda presenta una imagen del ilustrador Maurizio Quarello del álbum ilustrado "Titiritesa" para "detectar las concepciones espontáneas que tiene el alumnado sobre la diversidad sexual, mediante preguntas como: ¿Qué os dice la imagen? ¿Qué ocurre? ¿Qué os transmite?". Se trata de sacar a la luz todos los estereotipos, prejuicios e ideas que el alumnado tenga sobre el colectivo LGTBIQ, para después ver el corto "Animados en la diversidad". Ángela anima a comentar "Diverdiferencias: un cuento para acabar con la discriminación", material elaborado por Ideas sin Género de Chile, Colombia Diversa y el instituto de Género en Perú. Dado que la causa del acoso es un rechazo explícito hacia determinadas personas, sugiere "una dinámica social para observar el nivel de cohesión grupal a modo de diagnóstico y actividad introductoria", las metodologías que fomentan la interacción, la equidad, el aprendizaje cooperativo y la responsabilidad compartida es una forma de prevenir cualquier tipo de violencia. No cumplir con las normas de género asignadas culturalmente a hombres y mujeres son algunas de las causas más frecuentes de acoso escolar: motivan desde el insulto y la burla, hasta la exclusión y la violencia física. Por ello conviene no minimizar el problema, invisibilizarlo o tratar de justificarlo. La intervención frente al acoso escolar por homofobia o transfobia es una responsabilidad que el personal docente y todos los miembros de la comunidad educativa deben cumplir y hacer cumplir en el desarrollo de sus tareas, más allá de las creencias o ideologías personales (PARRAL, 2011).

En cualquier caso, tanto para el tratamiento de aspectos tan graves como es el ciberbullying (el acoso digital) como para repensar las posibilidades del uso educativo 


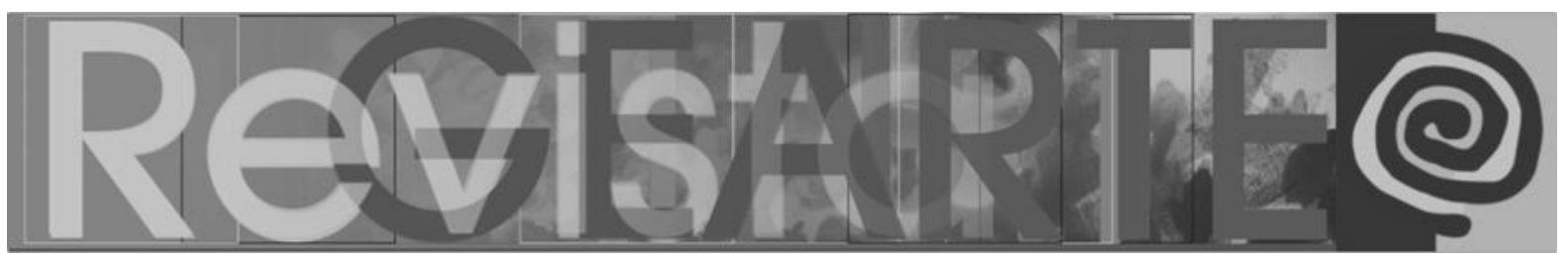

de las imágenes en internet, conviene plantearse hasta qué punto somos capaces de elaborar un lenguaje adecuado y pertinente al utilizar los entornos online en nuestras tareas cotidianas. $Y$ es que, para comprender la forma de interacción entre la cultura y la visión, no solamente debemos entender cómo funciona la vista, sino también desarrollar una mirada cultural, de manera que aprovechemos las respuestas diseñadas dese el cerebro y por supuesto las que llegan a él de manera no deseada. Nos relacionamos cada vez más con experiencias visuales ya construidas, lo que provoca que la distinción entre imagen y realidad se haga progresivamente más difusa. A tal efecto, desde los Estudios Visuales se intenta comprender e investigar sobre la cultura visual, ya que éstos no se ocupan únicamente de los objetos y artefactos visuales, sino que también abordan las relaciones y prácticas de subjetivación que generan (CALVELHE PANIZO, 2019).

Para formar parte de la ciudadanía digital se han de satisfacer ciertas condiciones, a saber: poseer habilidades al manejar la tecnología digital, disponer de acceso a las herramientas necesarias, tener acceso libre y constante a internet, desarrollando cotidianamente relaciones sociales en el ciberespacio. Todo ello nos lleva a plantearnos la importancia de que existan las condiciones favorables para la apropiación social de la tecnología, ya que las diferencias entre distintos segmentos de la población acerca del acceso a la tecnología digital seguirán siendo fuente de desigualdades por los diversos niveles de educación y de formación (HERNÁNDEZ, 2016). 


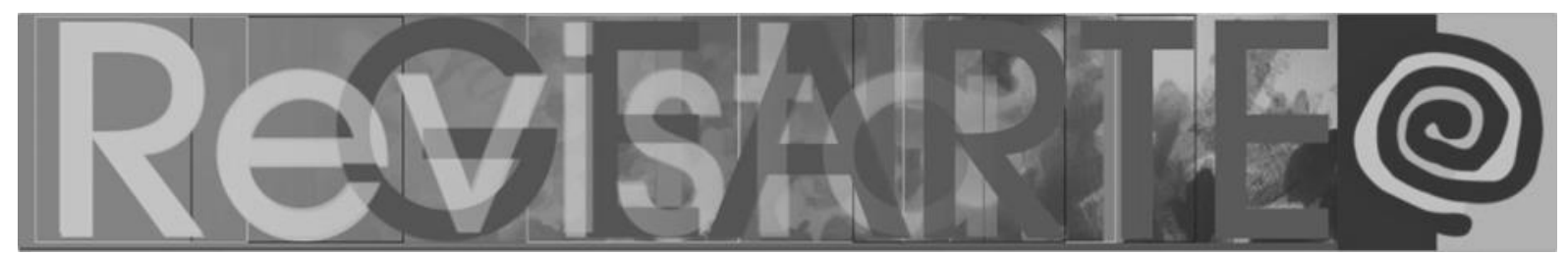

Figura 6 - "Lepidoptera Plebejus Idas". Fotografía manipulada. Obra del artista ecuatoriano Gledys Macías expuesta en Museari

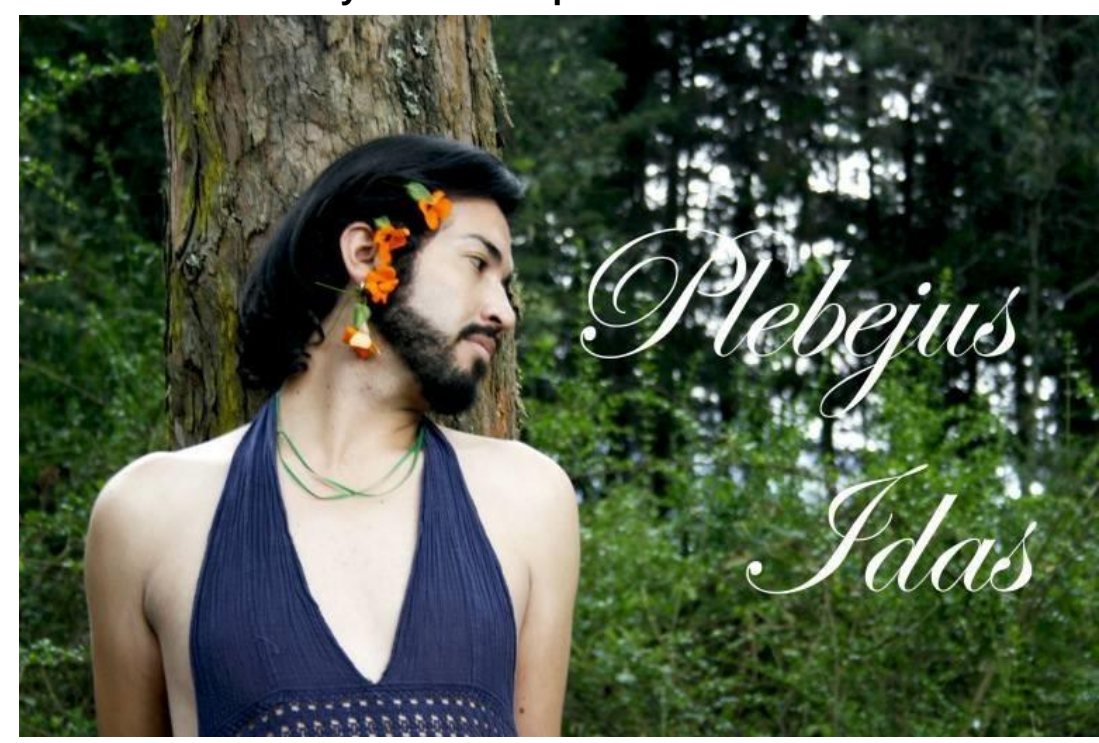

Fuente: https://www.museari.com/portfolio_page/gledys-macias/

Desde el reconocimiento de su orientación sexual, el artista se ha sentido motivado por la revalorización de lo que considera nuestro imaginario simbólico como LGBTI. La memoria, el derecho al auto-reconocimiento de la identidad y el erotismo, se han convertido en la parte más representativa de su trabajo. Lepidóptera que es una propuesta de exploración de la identidad de género a través de la vestimenta y de los usos cotidianos de la feminidad o la masculinidad. A mi alumnado les planteo el oficio de la enseñanza como un oficio muy feminizado (la mayoría de docentes en infantil y primaria son mujeres), y puede que por ello esté peor retribuido en los países de Iberoamérica (HUERTA, 2016). 


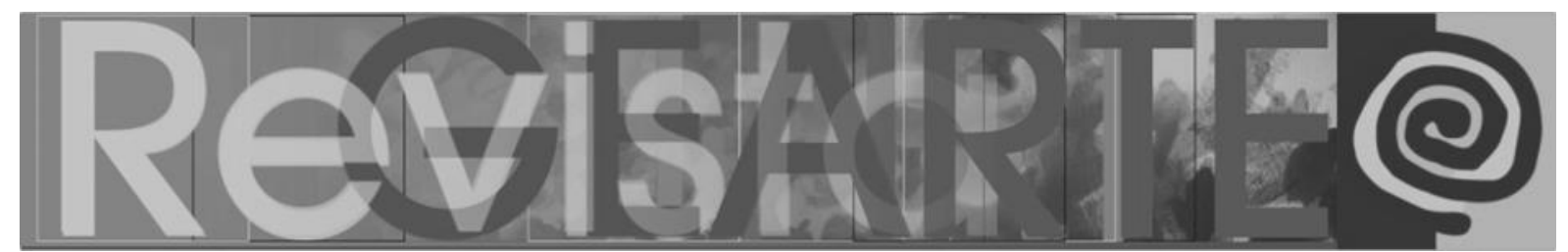

Figura 7 - "Collage 05". Obra del artista Alex Flemming presentada en Museari

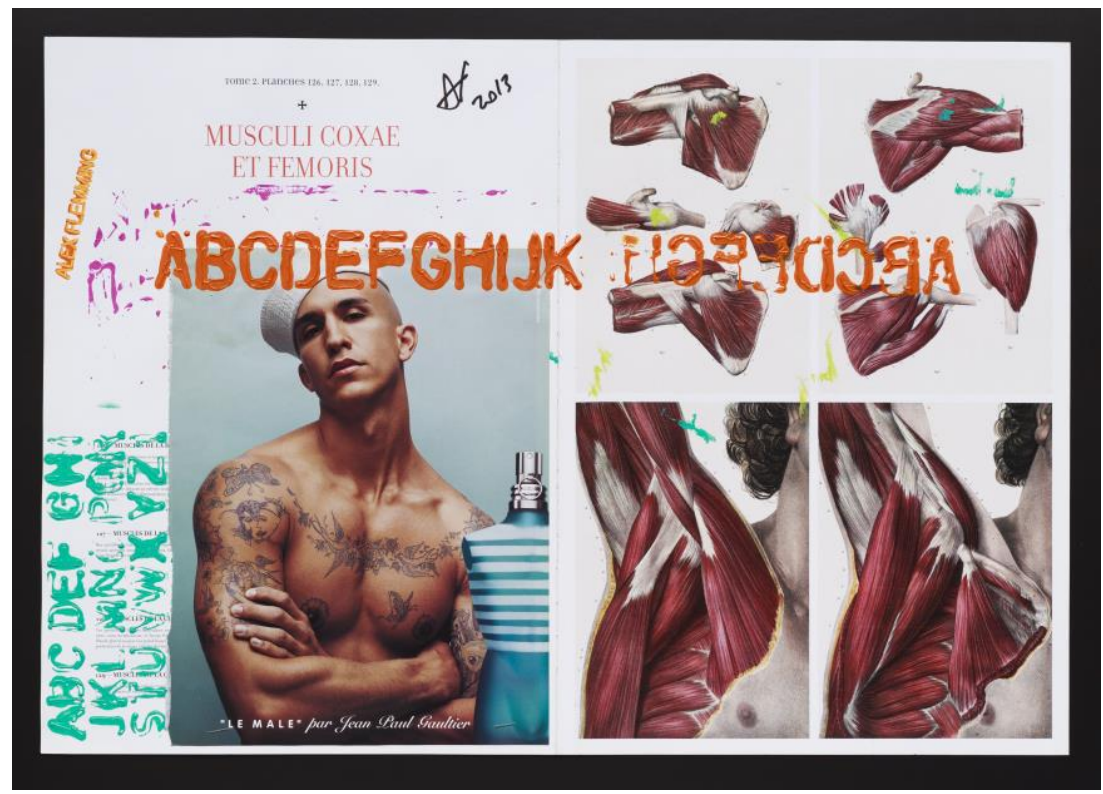

Fuente: cedida por el autor https://www.museari.com/portfolio_page/alex-flemming/

El artista brasileño afincado en Berlín Alex Flemming expone en Museari una serie ambientada en los contrastes del cuerpo aparentemente "perfecto" de los atletas. Siempre sorprendente y algo enigmático, Flemming es capaz de revisar su narrativa personal mediante el uso creativo de fotografías y recortes de libros, para reflejar la realidad social a través de retratos y acercamientos sugerentes a la piel de lo humano. Las letras del alfabeto llueven de manera sutil sobre sus ideas gráficas. Todos estos elementos gráficos nos permiten tratar en clase aspectos como el culto al cuerpo, la obsesión por los supuestos cuerpos perfectos, o el rechazo hacia los cuerpos no normativos. Es importante que los futuros docentes analicen estas cuestiones, para evitar comportamientos abusivos, y desde luego para dar cabida a la inclusión y la diversidad en nuestras aulas. 


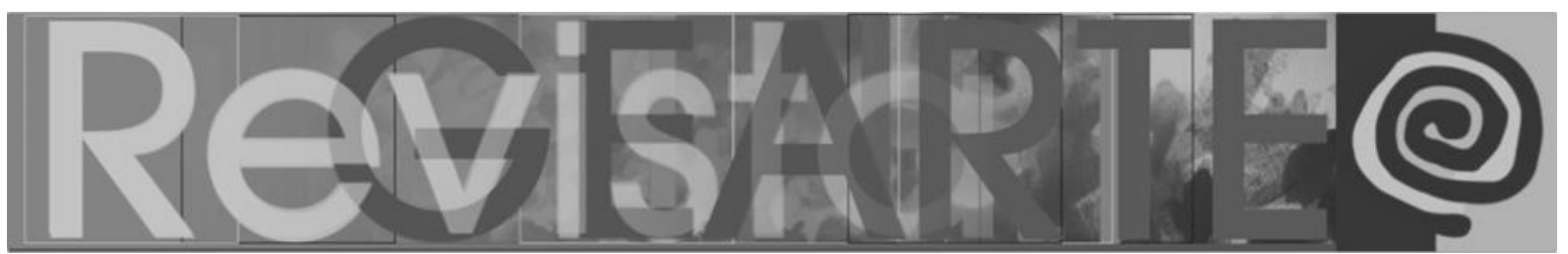

Figura 8 - "01". Obra de la artista Natividad Navalón presentada en Museari

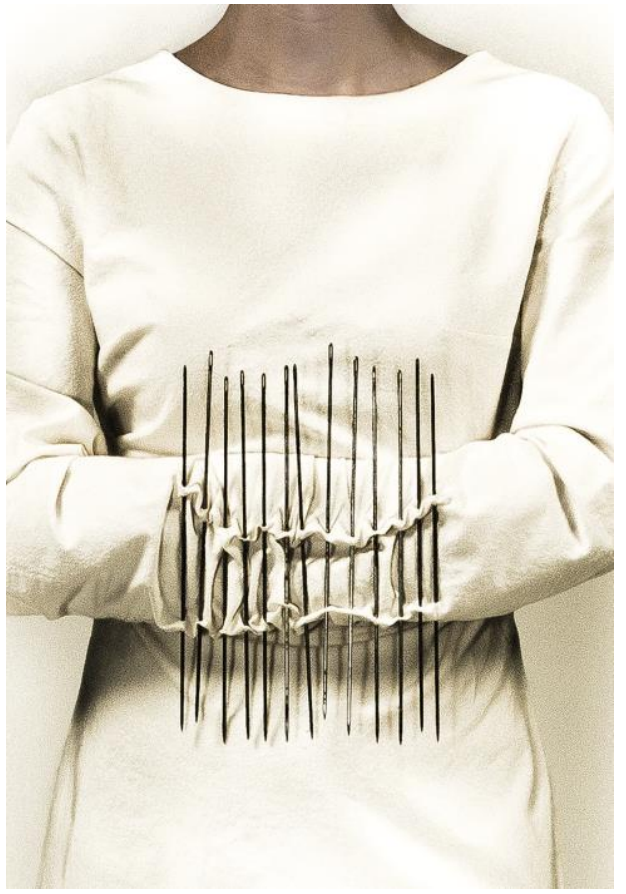

Fuente: https://www.museari.com/portfolio_page/natividad-navalon/

En la imagen de la Figura 8 vemos la pieza 1 de la serie "No lo llamaba hogar, pero era todo lo que ella tenía", de la artista Natividad Navalón. Su trabajo parte de la metáfora de indigencia, que es, en el fondo, una forma de comprender a la mujer, pero, sobre todo, una forma de comprendernos a nosotras mismas. Dice la artista que "nos hemos convertido en hijas de la indigencia, náufragas en busca de una isla, esa pequeña conquista del caos. A nosotras nos corresponde la puesta en cuestión de todo discurso, pero somos conscientes de que por mucho que nos desesperemos, ese camino lo estamos recorriendo solas." Este proyecto hace referencia al lugar de luchas y treguas en un campo yermo y a la necesidad de encontrar una zona segura que mantenga unidas, sin confundirlas, la presencia y la ausencia. Mujeres anónimas, heroínas en una sociedad misógina. La artista Natividad Navalón estuvo impartiendo una conferencia a nuestro alumnado de magisterio el pasado mes de abril de 2019.

El papel de las mujeres en el tejido docente de infantil y primaria resulta esencial. La mayoría de docentes son mujeres, y por ello merecen mayor atención. Es a través de piezas tan significativas y poderosas como las de la artista Natividad Navalón que 


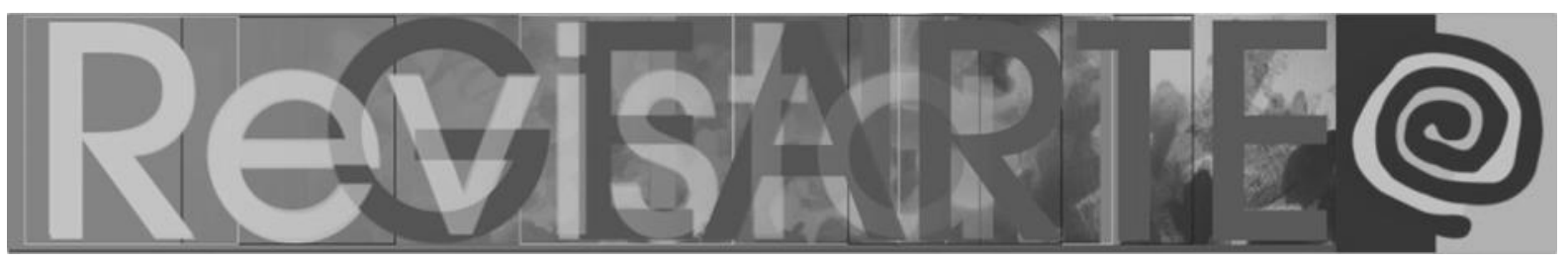

podemos conocer mejor los prejuicios y las vejaciones que padecen las mujeres en todo el mundo. El derecho a sus cuerpos, la posibilidad de ser libres tanto a nivel personal como profesional, la necesidad de facilitar las cuestiones de la atención a los hijos como de poder acercarse a sus verdaderas necesidades, nos obliga a realizar análisis en profundidad de lo que supone ser mujer en nuestra sociedad. Reparando en todas estas problemáticas, hemos de prestar atención a lo que miramos y a cómo se conforman nuestras miradas sobre nosotros y sobre el mundo, puesto que se "tiende a entrar en un discurso que elude tensiones, cuando el comunitarismo ciudadano entra en escena y cuando la noción de ciudadano y sabio digital se convierte en línea de un horizonte social y educacional” (SANCHO, HERNÁNDEZ; RIVERA, 2016, p. 34).

\section{Conclusiones}

El proyecto Museari ha supuesto la creación y el uso de la tecnología digital para lograr una serie de objetivos culturales y llevar a cabo acciones educativas que integran los mundos del arte, la historia, la educación artística y la defensa de los derechos humanos. Con esta herramienta ágil y accesible hemos podido introducir en la formación universitaria de docentes la temática de la defensa de los derechos LGTB. También permite acompañar las clases de arte en el resto de niveles educativos, animando y asesorando trabajos de otros profesores interesados por la temática. Esto supone incorporar las cuestiones relativas a los derechos de las personas y colectivos LGTB en el currículum universitario y en el resto de etapas educativas. Conseguimos visibilizar las problemáticas sociales y personales de los colectivos LGTB, al tiempo que analizamos las imágenes con las que identificamos a dichas personas y colectivos. Estamos interesados en concienciar al alumnado de la importancia de tratar estas cuestiones con la máxima naturalidad, reflexionando sobre aspectos tan graves como el bullying, revisando hasta qué punto resulta necesario atajar este grave problema en los entornos educativos. Explicamos las peculiaridades de cada caso que pueda darse, ya que en los colectivos LGTB existen personas homosexuales, bisexuales, transgénero y transexuales, y es bueno acercarse a conceptos menos conocidos como la cisexualidad o la intersexualidad. Asumimos el 


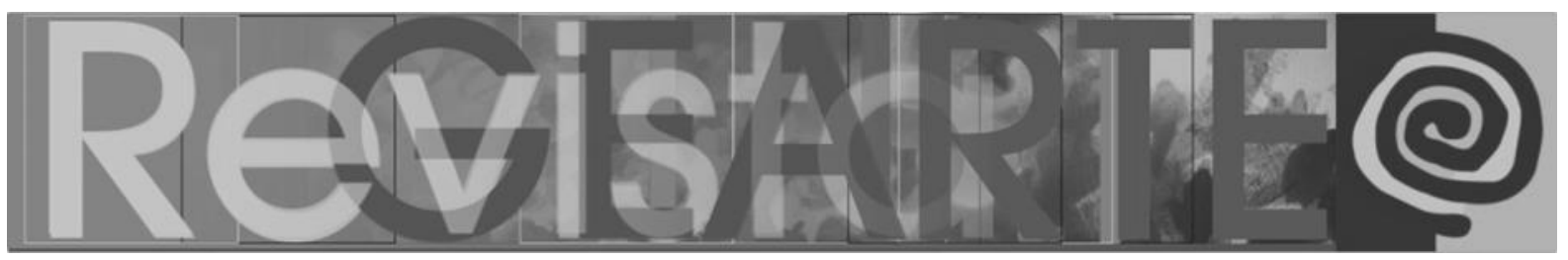

reto de eliminar la homofobia y la transfobia de los entornos educativos, y por supuesto en cualquier otro entorno.

Como docentes de educación artística, hemos comprobado que el alumnado recibe este tipo de informaciones con el máximo interés, debido a que anteriormente no se habían tratado lo suficiente en clase. Nos aseguran que son temas sobre los que hablan de forma habitual en sus conversaciones coloquiales, pero que nunca se escuchan voces de especialistas en estas temáticas. El hecho de hablar sin condicionantes nos permite eliminar preconceptos absurdos y anquilosados que suelen predominar entre la mayoría de la población respecto a estas temáticas vinculadas a los derechos humanos y la diversidad sexual. En tal sentido, urge contemplar el peso de las religiones y los tabúes en la invisibilidad de tales cuestiones. Conviene exponer en clase las opiniones que se tienen sobre estos temas y hablar abiertamente de sexualidad sin eliminar un concepto clave como es el deseo. Manejar la tecnología digital permite elaborar discursos ampliados, tejiendo provechosas relaciones en red muy atractivas por el dinamismo que imprime la inmediatez. El uso de Museari potencia otras actividades como puedan ser: visionar fragmentos de películas en las que se tratan cuestiones de bullying homofóbico; leer obras literarias donde aparecen ideas sobre la sexualidad, el placer y el deseo, sin miedos ni preconcepciones; anular los estigmas en terminologías como homosexualidad o transexualidad; y por supuesto incorporar terminología adecuada y respetuosa a nuestro vocabulario habitual. En última instancia, y en términos educativos, culturales, sociales y tecnológicos, siempre conviene aclarar que el problema no es la homosexualidad: el problema es la homofobia. Como docentes responsables de superar todas estas barreras, estamos en condiciones de superar todas las cohibiciones y tabúes si con ello permitimos avanzar en el respeto a la diversidad. 


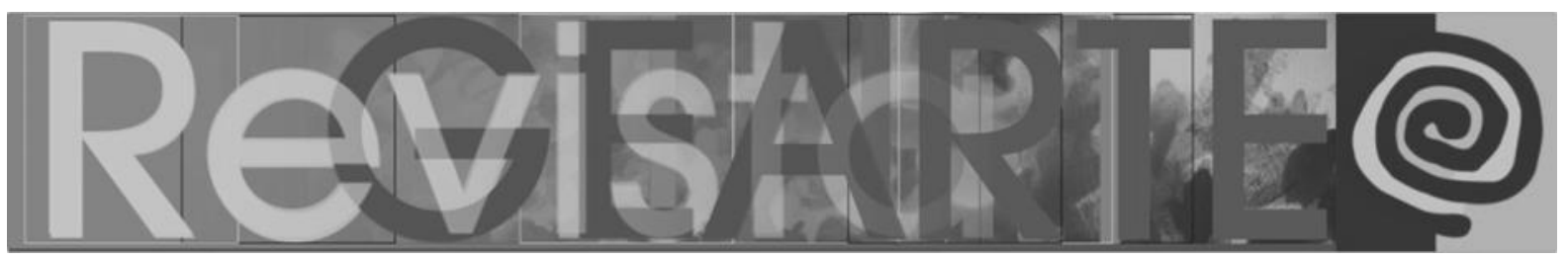

\section{Referencias}

ALIAGA, Juan Vicente. Arte y cuestiones de género. Donostia: Nerea, 2004.

AMARAL, Maria das Vitórias Negreiros do. Arte/Educação e feminismo no imaginário pernambucano como resistência política e formação identitária das mulheres. Revista Gearte, v. 6, n. 2, p. 247-271, maio/ago. 2019. http://dx.doi.org/10.22456/2357-9854.94281

BALLÓ, Jordi. Imatges del silenci: els motius visuals al cinema. Barcelona: Empúries, 2000.

BARTHES, Roland. Lo obvio y lo obtuso: imágenes, gestos, voces. Barcelona: Paidós,1982.

BUTLER, Judith. Deshacer el género. Barcelona: Paidós, 2006.

CALVINO, Italo. Seis propuestas para el próximo milenio. Madrid: Siruela,1995.

CALVELHE PANIZO, Lander. Adolescentes gays en la era digital: orientaciones para la educación. Alteridad, v. 14, n. 1, p. 65-75. 2019. https://doi.org/10.17163.alt.v14n1.2019.05

COSTA, Fábio José Rodrigues da. Ensino/Aprendizagem das Artes Visuais na América Latina: colonialidade cultural e emocional aliada a questões LGBT. Revista Gearte, Porto Alegre, v. 6, n. 2, p. 197246, maio/ago. 2019. http://dx.doi.org/10.22456/2357-9854.92908

COUNCIL OF EUROPE. Report on discrimination on grounds of sexual orientation and gender identity in Europe. Paris: Council of Europe, 2011.

DELEUZE, Gilles; GUATTARI, Felix. Mil mesetas: capitalismo y esquizofrenia. Valencia: Pre-Textos, 2004. ERIBON, Didier. La societé comme verdict. Paris: Flammarion, 2014.

EVEN-ZOHAR, Itamar. Polysystem theory: poetics today, v. 11, n. 1, p. 9-26, 1990.

FOUCAULT, Michel. Vigilar y castigar: nacimiento de la prisión. México: Siglo XXI, 1998.

FREEDMAN, Kerry. Interpreting gender and visual culture in art classrooms. Studies in Art Education, v. 35, n. 3, p. 157-70, 1994.

FROST, Stuart. The Warren Cup: highlighting hidden histories. International Journal of Art and Design Education, v. 26, n. 1, p. 63-72, 2007.

HAMLIN, Jessica; FUSARO, Joe. Contemporary strategies for creative and critical teaching in the 21st century. Art Education, v. 71, n. 2, p. 8-15, 2018. https://doi.org/10.1080/00043125.2018.1414529

HERNÁNDEZ, Fernando. Teaching the unknown to facilitate the emergence of a pedagogical event. Visual Inquiry: Learning \& Teaching Art, n. 5, v. 1, p. 87-95, 2016. https://doi.org/10.1386/vi.5.1.87_1

HERNÁNDEZ, Fernando; SANCHO, Joana Maria; RIVAS, José Ignacio. (Orgs.). Historias de vida en educación: biografías en contexto. Barcelona: Esbrina - Universitat de Barcelona, 2011.

HUERTA, Ricard. Maestros y museos: educar desde la invisibilidad. Valencia: PUV, 2010.

HUERTA, Ricard. Mujeres maestras de Perú: investigar en educación artística transitando entornos formales e informales. Revista Gearte, Porto Alegre, v. 3, n. 3, p. 427-443, set./dez. 2016.

HUERTA, Ricard. Transeducar. arte, docencia y derechos LGBT. Barcelona: Egales, 2017.

HUERTA, Ricard. Arte para primaria. Barcelona: UOC, 2019.

HUERTA, Ricard; ALONSO-SANZ, Amparo. Entornos informales para educar en artes. Valencia: PUV, 2017.

HUERTA, Ricard; ALONSO-SANZ, Amparo; RAMON, Ricard. De película: cine para educar en diversidad. Valencia: Tirant lo Blanch, 2019.

HUERTA, Ricard; CALLE, Román de la. Patrimonios migrantes. Valencia: PUV, 2013.

HUERTA, Ricard; NAVARRO, Germán. Museari. An online Museum about Sexual Diversity. Museum Education and Accessibility. Bridging the Gaps, Washington: CECA-ICOM, p. 145-149, 2016.

KRAHE, Amelia M. Arts Equity: A Praxis-Oriented Tale. Studies in Art Education: A Journal of Issues and Research, n. 58, v. 4, p. 267-278, 2017.https://doi.org/10.1080/00393541.2017.1368293 


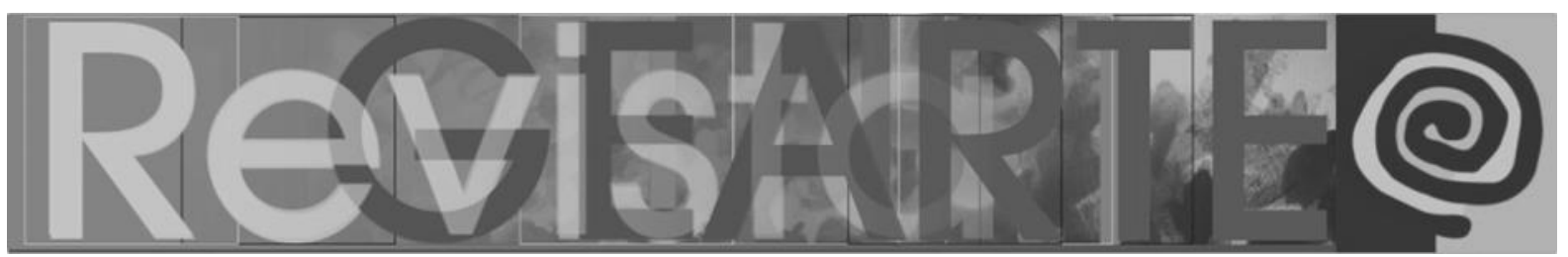

LADDAGA, Reinaldo. Estética de la emergencia. Buenos Aires: Adriana Hidalgo Editorial, 2006.

LORD, Catherine; MEYER, Richard. Art \& Queer Culture. London: Phaidon, 2013.

MORENO, Octavio; PUCHE, Luis. (Eds.). Transexualidad, adolescencias y educación: miradas multidisciplinares. Madrid: Egales, 2013.

NAVARRO, Germán. Iconografía de la homofobia: una propuesta de trabajo para secundaria. Aula de Secundaria, n. 10, p. 10-14, 2014.

NAVARRO, Germán. Museari Queer Art: el projecte Arteari en las Naves. València: Espai d'Art Fotogràfic, 2019. Accesible en https://www.museari.com/wp-content/uploads/pdf/CatalogoMuseariQueerArt.pdf

PANCIROLI, Chiara. Los bienes culturales como patrimonio educativo. EARI Educación Artística Revista de Investigación, v. 7, p. 86-99, 2016. https://doi.org/10.7203/eari.7.8158

PARRAL, Víctor. Contra la homofobia y la transfobia. Cuadernos de Pedagogía, n. 414, p. 72-74, 2011.

PATIÑO, Antón. Todas las pantallas encendidas: hacia una resistencia creativa de la mirada. Madrid: Fórcola, 2017.

PLANELLA, Jordi. El oficio de educar. Barcelona: UOC, 2014.

PICHARDO, José Ignacio. Abrazar la diversidad. Madrid: Instituto de la Mujer, 2015.

ROBINSON, Kerry H. (Org.). Growing up Queer: issues facing young australians who are gender variant and sexuality diverse. Melbourne: Young and Well, 2014.

ROLLING, James H. Art + Design Practice as Global Positioning System. Art Education, v. 70, n. 6, p. 4-6, 2017. https://doi.org/10.1080/00043125.2017.1361756

SANCHO, Joana Maria; HERNÁNDEZ, Fernando; RIVERA, Pablo. Visualidades contemporáneas, ciudadanía y sabiduría digital: afrontar las posibilidades sin eludir las tensiones. Relatec Revista Latinoamericana de Tecnología Educativa, v. 15, n. 2, 2016. https://doi.org/10.17398/1695-288X.15.2.25

TIN, Louis-Georges. Diccionario Akal de la Homofobia. Madrid: Akal, 2012.

UNESCO. Education Sector Responses to Homophobic Bullying. París: UNESCO, 2012.

\section{Ricard Huerta}

Artista y educador en artes. Catedrático de Universidad de Educación Artística. Profesor en la Facultat de Magisteri de la Universitat de València (España). Investigador del Instituto Universitario de Creatividad e Innovaciones Educativas. Director de EARI Educación Artística Revista de Investigación $<w w w . r e v i s t a e a r i . o r g>$ Director del Diploma de Posgrado Educación Artística y Gestión de Museos. Presidente de AVALEM Asociación Valenciana de Educadores de Museos. Director de Museari $<$ www.museari.com> Doctor en Bellas Artes y licenciado en Música, Bellas Artes y Comunicación Audiovisual. Coordinador del Grupo CREARI de Investigación en Pedagogías Culturales (GIUV2013103). Entre sus publicaciones recientes se encuentran La ciudad y sus docentes. Miradas desde el arte y la educación (UOC, Barcelona, 2015), Transeducar Arte, docencia y derechos LGBT (Egales, MadridBarcelona, 2016) y Arte para Primaria (UOC, Barcelona, 2019).

ORCID: https://orcid.org/0000-0002-1430-3198

E-mail: ricard.huerta@uv.es

Currículo: https://uv.academia.edu/ricardhuerta

Recebido em 06 de agosto de 2019 Aceito em 14 de dezembro de 2019 